\title{
Factors affecting breeding synchronization in an African bush squirrel (Paraxerus cepapi cepapi)
}

\author{
Susanna Viljoen \\ Mammal Research Institute, University of Pretoria, South Africa
}

Little is known about the bush squirrel, Paraxerus cepapi cepapi, which occurs in southern Africa in the northern part of the Transvaal Province, South Africa, southern Botswana and the southern part of Rhodesia. During a 2-year study of the life history of the subspecies near Naboomspruit $\left(28^{\circ} 47^{\prime} \mathrm{E}, 24^{\circ} 35^{\prime} \mathrm{S}\right)$, Transvaal, it was found that the animals are territorial, nest in holes in trees in family groups of 2-12 (mean $=5$ ), are mainly vegetarian (flowers, fruit, seeds) but also feed on insects, and that they breed seasonally with a mean litter size of 2 (Viljoen, 1975a). A distinct 'oestrous vocalization', which attracts males from adjoining territories to take part in the mating chase, is given by females during the period of mating activity which lasts for $5-6 \mathrm{~h}$ from sunrise to midday. Observations on the synchronizing effect of this call on oestrus are reported in this paper, together with other details of the reproduction of the animals.

Thirty squirrels were marked (toe-clipped and fur dyed) and observed in their natural habitat throughout 1973 and 1974, while data on gestation period and mating behaviour were obtained from 6 captive animals caged as 3 pairs close to each other. In addition, the ovaries of 37 animals collected throughout 1973 (Viljoen, 1975a) were fixed in Bouin's fluid and, after routine paraffin-wax embedding, sectioned serially at $5 \mu \mathrm{m}$. Every twentieth section was mounted and stained in Mallory (Gray, 1954). Measurements of the largest follicle in each ovary and of corpora lutea were recorded according to the method of Mossman \& Duke (1973), and vesicular follicles were counted throughout each ovary.

Table 1. Dates of oestrus and inter-oestrous interval (days) in parentheses of three bush squirrels

\begin{tabular}{|c|c|c|c|c|c|c|}
\hline & \multicolumn{5}{|c|}{1974} & \multirow{2}{*}{$\frac{1975}{\text { January }}$} \\
\hline & March & June & August & October & November & \\
\hline 1 & & $19(58)$ & $16(60)$ & $15(30)$ & 14 & \\
\hline 2 & $3(107)$ & $18(63)$ & $19(63)$ & $19(31)$ & $19(60)$ & 18 \\
\hline 3 & & & $13(64)$ & $16(28)$ & $13(60)$ & 12 \\
\hline
\end{tabular}

Breeding synchronization. The occurrence of the oestrous vocalization was taken as an indication of oestrus, and as shown in Table 1 the 3 caged females exhibited synchrony. Vocalization by one of the females or from a tape recording usually elicited vocalization from the others, within a few days. Although effective in September and November 1974, the tape recording had no effect in July 1975. The coincidence of the appearance of oestrus seemed to be independent of whether or not the females conceived. The oestrous call thus appears to be the initiation of oestrus, provided the follicular apparatus is sufficiently developed.

Further evidence for breeding synchronization was obtained from field observations (Table 2), most young being born within a 1-week period in November. Measurements of body weight of the squirrels (Viljoen, 1975a) indicated that there was less food available in 1974 than in 1973 and the 'sporadic' litters in 1973 could have been related to food availability. Other factors such as male presence and seasonality are probably also important because one of the captive females, who had produced 6 litters in 1972, did not come into oestrus from February to July 1973 when the testes of her mate had regressed considerably.

If nutrition does play a role, breeding synchronization could enable the greatest number of young within a small group to attain adult weight. Viljoen (1975a) showed that juvenile bush squirrels 
Table 2. Dates of birth of litters in five groups of bush squirrels on the study area

\begin{tabular}{lccccccc}
\hline & \multicolumn{1}{c}{1972} & \multicolumn{3}{c}{1973} & & 1974 \\
\cline { 2 - 5 } \cline { 5 - 7 } & November & & March & May & June & November & January \\
\hline No. of young & 11 & 1 & 3 & 2 & 12 & 3 \\
No. of litters & 7 & 1 & 2 & 1 & 5 & 2 \\
\hline
\end{tabular}

born in November 1973 had an extremely high survival rate until the following July. Most losses occurred between July and September when food is scarcest, and when many of the young are being chased out of the group by the adults. When more than one litter is born in a single nest to different females (one nest record is of 3 adult $Q q, 2$ adult $\delta \hat{o}$ and 7 young), the young would have a greater chance of survival if they were all equally matched in age, weight and consequently in strength at the inevitable food fights. It is also possible that, in bush squirrels, breeding synchronization could have a group acceptance function: e.g. Zimmermann (1974) found that 22 thirteen-lined ground squirrel (Spermophilus tridecemlineatus) young from 3 litters were born within an 8-h time span, but of 8 young introduced later, 7 were cannibalized.

Breeding synchronization by oestrous vocalization as observed in $P$. $c$. cepapi has not been described in sciurids or, as far as is known, in any other mammal. However, Muul \& Lim(1974) found that Malaysian flying squirrels, Hylopetes lepidus, showed highly synchronized breeding although they had a super-annual breeding interval and Farentinos (1972) described tassel-eared squirrels, Sciurus aberti ferreus, on his study area as having six mating bouts within a short period. Further investigations might reveal synchronization of breeding in other sciurids.

Post-partum oestrus. Ovaries from visibly pregnant animals had well developed vesicular follicles (Table 3), the diameters of which increased as term approached, suggesting that ovulation and oestrus might occur at parturition. The ovaries of some females contained corpora lutea and smaller vesicular follicles but there was no visible fetus.

Table 3. Differences in the mean ovarian characteristics of adult bush squirrels collected from the Transvaal during 1973

\begin{tabular}{|c|c|c|c|c|c|}
\hline No. of animals & Visibly pregnant & $\begin{array}{l}\text { Ovarian wt } \\
\text { (mg) }\end{array}$ & $\begin{array}{c}\text { Diam. of } \\
\text { largest vesicular } \\
\text { follicle }(\mu \mathrm{m})\end{array}$ & $\begin{array}{l}\text { No. of vesicular } \\
\text { follicles/ovary }\end{array}$ & $\begin{array}{c}\text { Diameter of CL } \\
(\mu \mathrm{m})\end{array}$ \\
\hline 5 & Yes & $15 \cdot 0$ & $475 \cdot 2$ & $26 \cdot 8$ & $1023 \cdot 5$ \\
\hline 5 & No & $14 \cdot 4$ & 393.4 & $5 \cdot 3$ & $851 \cdot 5$ \\
\hline 18 & No & $10 \cdot 0$ & $365 \cdot 7$ & $8 \cdot 6$ & None present \\
\hline
\end{tabular}

The gestation period of captive animals was established as 56.5 days $(\mathrm{N}=4)$ and one captive female produced 6 consecutive litters in 1 year by conceiving at the post-partum oestrus. Direct observations indicated that oestrus occurred on the 4th (twice) or 5th (once) day after parturition in one captive female. However, the expression of oestrus may be influenced by more than one factor, because this female did not become oestrous (did not vocalize) after parturition in January 1974 when there was no adult male present but did so in January 1975 when a male was present. A field-caught female produced 2 young 1 day after capture, but, in the absence of a male, she also failed to come into subsequent oestrus. It therefore seems possible that the presence and behaviour of the male (probably specifically the male murmur vocalization which increases in frequency of occurrence as the testes enlarge with the approach of the breeding season-Viljoen, 1975a) could play a role in inducing oestrus.

Amongst sciurids, a post-partum oestrus has been observed in the pigmy squirrel, Exilisciurus exilis (Conaway, 1968), and in the American red squirrel, Tamiasciurus hudsonicus (Millar, 1970). In the latter species Millar found that it was an erratic feature occurring in one year but not the next. These observations are contrary to the statement by Asdell (1964) that there is apparently no oestrus or ovulation until lactation is terminated in sciurids. 
Breeding season. Measurements of scrotal diameter, testicular weight, testis tubule diameter and epididymal sperm counts have shown that male bush squirrels have a breeding season (Viljoen, 1975b). In females the ovaries contained more (10.3-24.5/ovary) and larger (450.5 $\mu \mathrm{m}$ in diameter) vesicular follicles from August to December than in April-July (1.3-13.5/ovary and 358.9 $\mu \mathrm{m}$ in diameter). However, breeding can occur throughout the year and although most young were born during November, litters were also seen in the middle of 1973 (but not in 1974). Smithers (1968) found no pronounced breeding season in Botswana where pregnant females were present throughout the year although there were larger numbers of pregnancies in November and December. However, variation in breeding performance might be masked by nutritional influences.

Further study of the reproductive processes of this sciurid is clearly required.

I thank Mr E. A. Galpin for allowing the field work to be done on his farm and Professor J. D. Skinner for commenting on the manuscript and all his encouragement.

\section{References}

AsDell, S.A. (1964) Patterns of Mammalian Reproduction, 2nd edn. Cornell University Press, Ithaca, New York.

Conaway, C.H. (1968) Post-partum oestrus in a sciurid Exilisciurus exilis. J. Mammal. 49, 158-159.

FARENTINos, R.C. (1972) Social dominance and mating activity in the tassel-eared squirrel (Sciurus aberti ferreus). Anim. Behav. 20, 316-326.

GRAY, P. (1954) The Microtomist's Formulary and Guide. Constable and Co. Ltd, London.

MILlAR, J.S.(1970) The breedingseason and reproductive cycle of the western red squirrel. Can. J. Zool. 40, 471-473.

Mossman, H.W. \& DUke, K.L. (1973) Comparative Morphology of the Mammalian Ovary. University of Wisconsin Press, Madison.
Mưl, I. \& LIM, B.L. (1974) Reproductive frequency in Malaysian fiying squirrels, Hylopetus and Pteromyscus. J. Mammal. 55, 393-400.

Smithers, R.H.N. (1968) The Mammals of Botswana. National Museums of Rhodesia, Salisbury.

ViLJOEN, S. (1975a) Aspects of the ecology, reproductive physiology and ethology of the bush squirrel, Paraxerus cepapi cepapi. M.Sc. thesis, University of Pretoria.

ViLJOEN, S. (1975b) Aspects of reproduction of male bush squirrel, Paraxerus cepapi cepapi (A. Smith, 1836) in the Transval. Publ. Univ. Pretoria. New Series 97, 86-91.

ZimmermanN, G.D. (1974) Co-operative nursing behaviour observed in Spermophilus tridecemlineatus (Mitchik). J. Mammal. 55, 680-681. 